\title{
NON-CULTURAL DETECTION OF NEISSERIA GONORRHOEAE IN CERVICAL AND VAGINAL WASHINGS
}

\author{
H. Young, S. K. Sarafian, A. B. Harris and A. McMillan* \\ Department of Bacteriology, University Medical School, Teviot Place, Edinburgh EH8 \\ $9 A G$ and ${ }^{*}$ Department of Genito-Urinary Medicine, The Royal Infirmary, Edinburgh \\ EH39WY
}

\begin{abstract}
SUmmary. Genetic transformation, an indirect sandwich enzymelinked immunosorbent assay (ELISA) and the Limulus amoebocyte assay were used to indicate the presence of products of Neisseria gonorrhoeae in vaginal and uterine cervical aspirates from 37 women attending a Department of Genito-Urinary Medicine. In parallel with these tests, qualitative and quantitative assessments of the microbial content of aspirates were made. There was wide variation in the numbers of gonococci cultured. The mean viable count for cervical aspirates was $1 \times 10^{6} \mathrm{cfu} / \mathrm{ml}$ and the range was $\left(5 \times 10^{3}\right)-\left(8 \times 10^{6}\right) \mathrm{cfu} / \mathrm{ml}$; the mean count for vaginal aspirates was $8.4 \times 10^{4} \mathrm{cfu} / \mathrm{ml}$ and the range $\left(1 \times 10^{2}\right)-\left(1 \times 10^{6}\right) \mathrm{cfu} / \mathrm{ml}$. Viable counts of organisms other than gonococci in vaginal aspirates were two to tenfold greater than the corresponding counts for cervical aspirates. Of 20 patients with gonorrhoea confirmed by conventional diagnostic cultures, aspirates from $15(75 \%)$ gave a positive transformation result, and $12(60 \%)$ a positive ELISA result; $16(84 \cdot 2 \%)$ out of 19 of these aspirates tested by the Limulus lysate assay were positive at a dilution of 1 in 100.
\end{abstract}

\section{INTRODUCTION}

Most methods for the laboratory diagnosis of gonorrhoea rely on culture and therefore depend upon maintaining the viability of Neisseria gonorrhoeae (Young, 1981). Recently, alternative approaches to the diagnosis of gonorrhoea, based upon the detection of gonococcal components in clinical specimens have been developed. These include detection of antigen in urine by solid-phase radioimmunoassay (Thornley et al., 1979), detection of gonococcal DNA by genetic transformation (Bawdon, Juni and Britt, 1977), the Limulus amoebocyte lysate assay for endotoxin (Spagna, Prior and Perkins, 1979 and 1980), gas liquid chromatography (Sud and Feingold, 1979), and the detection of the enzyme 1,2-propanediol oxidoreductase (Takeguchi et al., 1980).

Unfortunately, qualitative and quantitative assessments of the microbial content of cervical and vaginal aspirates have not been performed in parallel with the 
development of the various tests. Lowe and Kraus (1976) found that the numbers of gonococci in cervico-vaginal aspirates from 52 women with gonorrhoea ranged from $40-1.8 \times 10^{6} \mathrm{cfu} / \mathrm{ml}$ (mean $1.45 \times 10^{4} \mathrm{cfu} / \mathrm{ml}$ ). Recently we reported that an indirect sandwich enzyme-linked immunosorbent assay (ELISA) could detect gonococci within this range with clinical isolates and in a simulated clinical specimen (Sarafian and Young, 1982). Earlier studies (Sarafian and Young, 1980) had also shown that genetic transformation was capable of detecting numbers of gonococci within this range. The aim of the present study was to examine the value of these methods, and the Limulus lysate assay, in parallel with a quantitative microbiological investigation of cervical and vaginal aspirates.

\section{MATERIALS AND METHODS}

Study population. Thirty seven women attending the Department of Genito-Urinary Medicine, The Royal Infirmary, Edinburgh, were investigated; 25 of them were known contacts of men with urethral gonorrhoea and 12 were not known to be contacts.

Specimens. These were taken from the urethra and cervix for microscopic examination and culture, and from the rectum for culture only. Wet films of vaginal secretions were examined microscopically for the detection of Trichomonas vaginalis, and gram-stained smears for Candida albicans. Cervical secretions were collected from the endocervical canal as previously described (Young, Sarafian and McMillan, 1981).

To collect vaginal secretions, pyrogen-free saline $(5 \mathrm{ml})$ was instilled into the posterior fornix of the vagina through a sterile polythene capillary tube (chromatography column tubing, internal diameter $1.0 \mathrm{~mm}$; Pharmacia Fine Chemicals, Uppsala, Sweden) attached to a $5 \mathrm{ml}$ syringe. After $30 \mathrm{~s}$ for equilibration, the washings were aspirated and expelled into a sterile, pyrogen-free, plastic Universal container (Sterilin).

Portions $(200 \mu \mathrm{l})$ of vaginal and cervical secretions were dispensed in small plastic containers; material was left in the pyrogen-free vials for the Limulus lysate assay. The secretions were stored at $-20^{\circ} \mathrm{C}$ until required.

Bacteriological investigation of vaginal and cervical secretions. Immediately after collection, cervical and vaginal secretions were mixed thoroughly by a vortex mixer.

Viable counts were performed by serially diluting secretions in tenfold steps in GC broth (Kellogg et al., 1963) up to a dilution of $10^{5}$ and spreading $0.1 \mathrm{ml}$ of each dilution on the following media: modified New York City medium (Young, 1978b), MacConkey agar (Oxoid), and blood agar (Oxoid). The counts on blood agar were performed in duplicate for aerobic and anaerobic incubation; the anaerobic methods were those of Collee et al. (1972). Plates were examined after incubation for 24 and $48 \mathrm{~h}$.

Statistical analysis. The Student's $t$ test was used to assess the difference between means.

Criteria for identification of isolates. N. gonorrhoeae was identified by the fluorescent-antibody test and the rapid carbohydrate-utilisation test (Young, 1978a). Chlamydia trachomatis was isolated by the method of Thomas et al. (1977) with cycloheximide-treated cells. For the isolation and identification of Ureaplasma urealyticum, $100 \mu \mathrm{l}$ of each specimen was transferred aseptically to $0.9 \mathrm{ml}$ of modified U9 medium (Young, Tuach and Bain, 1981). Serial tenfold dilutions were made up to a dilution of $10^{10}$. The vials were incubated under standard conditions and examined at 24 and $48 \mathrm{~h}$. The presence of $U$. urealyticum was indicated by a change of colour of the medium from yellow to pink. Candida albicans was identified on the basis of typical macroscopic and microscopic yeast-like morphology and the production of germ tubes (Taschdjian, Burchall and Kozinn, 1960).

The following organisms were identified according to the criteria outlined by Cowan (1974): Staphylococcus spp., haemolytic streptococci, enterococci (Streptococcus faecalis), lactobacilli, diphtheroids (diphtheroid-like organisms that were gram-variable, catalase negative and haemolytic were presumptively identified as Gardnerella vaginalis), Proteus spp., Escherichia coli, anaerobic streptococci, Bacteroides spp., Clostridium spp. 


\section{Detection of gonococcal components}

One portion from each of the 37 cervical and vaginal aspirates was thawed. All the specimens were processed in one batch by each of the following assays.

(i) Transformation assay. To each $200 \mu \mathrm{l}$ of aspirate, $200 \mu \mathrm{l}$ of saline citrate $(p \mathrm{H} 7 \cdot 4)$ containing sodium dodecylsulphate $0.05 \%(\mathrm{w} / \mathrm{v})$ was added and mixed thoroughly by a vortex mixer operated at full speed. The mixtures were incubated at $65^{\circ} \mathrm{C}$ for $1 \mathrm{~h}$ and processed as described by Sarafian and Young (1980). A proline auxotroph of $N$. gonorrhoeae strain F62 was used as recipient and a positive result was taken as the growth, on medium lacking proline, of $\geqslant 20$ colonies identical in size and appearance to the colonies of strain F62 growing on the same medium containing proline.

(ii) Indirect sandwich ELISA. The method was based on that of Sarafian and Young (1982). To $180 \mu \mathrm{l}$ of aspirate (preincubated at $56^{\circ} \mathrm{C}$ for $20 \mathrm{~min}$ to inactivate any intrinsic alkaline phosphatase), $20 \mu \mathrm{l}$ of PBS ( $p \mathrm{H} \mathrm{7.4)}$ was added; the molarity of the phosphate buffer was increased from $0.05 \mathrm{M}$ to $0.5 \mathrm{M}$ to allow for the tenfold dilution in the aspirate. $\mathrm{NaCl}$ was kept at $0 \cdot 15 \mathrm{M}$ because the secretions were aspirated with physiological saline. The concentrations of Tween 20 and sodium azide were increased to $0.5 \%(\mathrm{v} / \mathrm{v})$ and $0.2 \%(\mathrm{w} / \mathrm{v})$ respectively. After the addition of $200 \mu \mathrm{l}$ of sputolysin, the specimens were mixed thoroughly by vortex mixing and processed as described previously. Positive and negative controls were set up in duplicate; negative controls comprised antigen diluent instead of antigen and positive controls comprised a suspension of $N$. gonorrhoeae strain 9 in saline which was treated in the same manner as clinical specimens. An extinction value of $\geqslant 1.0$ at $405 \mathrm{~nm}$ was considered to be a positive result.

(iii) Limulus lysate assay. The assay was performed on the cervical secretions in pyrogen-free containers. The specimens were mixed thoroughly by vortex mixing, diluted in pyrogen-free water to a final dilution of 1 in 100, and processed as described by Young et al. (1981). A firm opaque gel that remained adherent to the bottom of the vial when inverted through $180^{\circ}$ was scored as positive.

After the correlation between the Limulus assay results and a diagnosis of gonorrhoea had been made, specimens that gave a positive result were retested at a dilution of 1 in 200 .

\section{RESULTS \\ Quantitative microbiology of cervical and vaginal aspirates}

Gonococci were detected in cervical or vaginal aspirates, or both, from 19 of the 25 known contacts of men with gonorrhoea. Viable counts for gonococci cultured from aspirates are given in table I. Routine cultures taken at the first examination were also positive for gonococci in these 19 patients. An additional patient gave a positive culture at the second examination. None of the specimens from the 12 women who were not known contacts yielded gonococci on culture.

The number of $N$. gonorrhoeae isolated from cervical aspirates varied within a range of $\left(5 \times 10^{3}\right)-\left(8 \times 10^{6}\right) \mathrm{cfu} / \mathrm{ml}\left(\right.$ mean $\left.1 \times 10^{6} \mathrm{cfu} / \mathrm{ml}\right)$; the corresponding values for vaginal aspirates were $\left(1 \times 10^{2}\right)-\left(1 \times 10^{6}\right) \mathrm{cfu} / \mathrm{ml}\left(\right.$ mean $\left.8.4 \times 10^{4} \mathrm{cfu} / \mathrm{ml}\right)$. The difference between the two means is not statistically significant $(t 1 \cdot 8,0 \cdot 1>\mathrm{p}>0.05)$.

Table II shows the frequency of isolation of each organism isolated from cervical and vaginal aspirates of 18 patients with and 15 patients without gonorrhoea. Quantitative data were not available for four of the patients in the study. When an organism was isolated from eight or more patients, the mean number of organisms present was calculated (table III).

\section{Detection of gonococcal components in cervical and vaginal aspirates}

The results obtained with specimens from the 20 patients with gonorrhoea are shown in table IV. 
TABLE I

Viable counts of $N$. gonorrhoeae in cervial and vaginal aspirates from 19 women with gonorrhoea

\begin{tabular}{c|cc}
\hline & \multicolumn{2}{c}{$\begin{array}{c}\text { Colony-forming units }\left(\times 10^{4}\right) / \mathrm{ml} \text { of } \\
\text { N. gonorrhoeae isolated from }\end{array}$} \\
\cline { 2 - 3 } $\begin{array}{c}\text { Patient } \\
\text { no. }\end{array}$ & Cervix & Vagina \\
\hline 1 & 2.4 & 0.6 \\
2 & 66.0 & 28.0 \\
10 & 5.0 & 0.2 \\
11 & 1.4 & 0.06 \\
13 & 2.8 & 0.3 \\
14 & 15.0 & 1.7 \\
15 & 230.0 & 104.0 \\
17 & 0.9 & 0.04 \\
18 & 18.0 & 0.3 \\
19 & 28.0 & 0.4 \\
22 & 800.0 & 4.0 \\
24 & 0.9 & $<0.01$ \\
29 & 580.0 & 1.7 \\
30 & 8.0 & 0.6 \\
31 & 37.0 & 0.1 \\
32 & 140.0 & $<0.01$ \\
33 & 0.7 & 0.01 \\
34 & 1.4 & 1.4 \\
36 & 0.5 & 0.02 \\
Mean & 102 & 8.4 \\
\hline
\end{tabular}

\section{TABLE II}

Qualitative assessment of microflora from cervical and vaginal aspirates of patients with and without gonorrhoea

\begin{tabular}{|c|c|c|c|c|}
\hline \multirow[b]{3}{*}{ Organism } & \multicolumn{4}{|c|}{$\begin{array}{l}\text { Number (percentage) of patients with and without } \\
\text { gonorrhoea from whom each organism was isolated } \\
\text { from cervical (C) or vaginal (V) aspirates }\end{array}$} \\
\hline & \multicolumn{2}{|c|}{$\begin{array}{l}\text { With gonorrhoea } \\
\quad(\mathrm{n}=18)\end{array}$} & \multicolumn{2}{|c|}{$\begin{array}{l}\text { Without gonorrhoea } \\
\qquad(\mathrm{n}=15)\end{array}$} \\
\hline & $\mathrm{C}$ & V & $\mathrm{C}$ & V \\
\hline $\begin{array}{l}\text { N. gonorrhoeae } \\
\text { S. albus } \\
\text { Haemolytic streptococci } \\
\text { Enterococci } \\
\text { Anaerobic streptococci } \\
\text { Lactobacilli } \\
\text { Diphtheroids } \\
\text { G. vaginalis } \\
\text { Clostridium spp. } \\
\text { Bacteroides bivius } \\
\text { E. coli } \\
\text { C. albicans } \\
T . \text { vaginalis } \\
\text { Chlamydia } \\
\text { U. urealyticum }\end{array}$ & $\begin{array}{l}17^{*}(94) \\
12(67) \\
0 \\
3(17) \\
1(6) \\
10(56) \\
10(56) \\
2(11) \\
0 \\
1(6) \\
0 \\
0 \\
\text { ND } \\
4(22) \\
15(83)\end{array}$ & $\begin{array}{l}15(83) \\
17(94) \\
0 \\
5(28) \\
2(11) \\
11(61) \\
11(61) \\
2(11) \\
1(6) \\
2(11) \\
0 \\
0 \\
0 \\
\text { ND } \\
15(83)\end{array}$ & $\begin{array}{l}0 \\
7(47) \\
2(13) \\
2(13) \\
1(7) \\
12(80) \\
8(53) \\
0 \\
0 \\
2(13) \\
1(7) \\
1(7) \\
\text { ND } \\
1(7) \\
12(80)\end{array}$ & $\begin{array}{l}0 \\
13(87) \\
4(27) \\
4(27) \\
2(13) \\
11(73) \\
8(53) \\
0 \\
0 \\
2(13) \\
1(7) \\
2(13) \\
3(20) \\
N D \\
12(80)\end{array}$ \\
\hline
\end{tabular}

* One patient with negative gonococcal cultures at the time of the quantitative examination gave positive cultures when tested one week later. $\mathrm{ND}=$ not done. 
TABLE III

Mean number, and range, of organisms isolated from patients with and without gonorrhoea

\begin{tabular}{|c|c|c|c|c|c|}
\hline \multirow{3}{*}{$\frac{\text { Organism }}{\text { N. gonorrhoeae }}$} & \multirow{3}{*}{$\begin{array}{c}\text { Site* }^{*} \\
\mathrm{C} \\
\mathrm{V}\end{array}$} & \multicolumn{4}{|c|}{ Mean cfu (range)/ml of aspirate from } \\
\hline & & \multicolumn{2}{|c|}{ Patients with gonorrhoea } & \multicolumn{2}{|c|}{ Patients without gonorrhoea } \\
\hline & & $\begin{array}{l}1.0 \times 10^{6} \\
8.4 \times 10^{4}\end{array}$ & $\begin{array}{l}\left(5.4 \times 10^{3}-8.0 \times 10^{6}\right) \\
\left(1.0 \times 10^{2}-1.0 \times 10^{6}\right)\end{array}$ & $\begin{array}{l}\cdots \\
\cdots\end{array}$ & $\cdots$ \\
\hline S. albus & $\begin{array}{l}\mathrm{C} \\
\mathrm{V}\end{array}$ & $\begin{array}{l}2.3 \times 10^{3} \\
1.9 \times 10^{4}\end{array}$ & $\begin{array}{l}\left(1.0 \times 10^{2}-1.2 \times 10^{4}\right) \\
\left(3.0 \times 10^{2}-1.0 \times 10^{5}\right)\end{array}$ & $5.8 \times 10^{4}$ & $\left(2.0 \times 10^{2}-3.8 \times 10^{5}\right)$ \\
\hline Lactobacilli & $\begin{array}{l}\mathrm{C} \\
\mathrm{V}\end{array}$ & $\begin{array}{l}5 \cdot 1 \times 10^{7} \\
7 \cdot 2 \times 10^{7}\end{array}$ & $\begin{array}{l}\left(2.0 \times 10^{3}-1.0 \times 10^{8}\right) \\
\left(4.8 \times 10^{3}-1.0 \times 10^{8}\right)\end{array}$ & $\begin{array}{l}1.7 \times 10^{7} \\
5.4 \times 10^{7}\end{array}$ & $\begin{array}{l}\left(1.0 \times 10^{3}-1.0 \times 10^{8}\right) \\
\left(2.0 \times 10^{5}-1.0 \times 10^{8}\right)\end{array}$ \\
\hline Diphtheroids & $\stackrel{\mathrm{C}}{\mathrm{V}}$ & $\begin{array}{l}1.7 \times 10^{7} \\
4.6 \times 10^{7}\end{array}$ & $\begin{array}{l}\left(4.0 \times 10^{3}-1.0 \times 10^{8}\right) \\
\left(2.4 \times 10^{3}-1.0 \times 10^{8}\right)\end{array}$ & $\begin{array}{l}1.4 \times 10^{7} \\
4.6 \times 10^{7}\end{array}$ & $\begin{array}{l}\left(1.0 \times 10^{4}-1.0 \times 10^{8}\right) \\
\left(2.0 \times 10^{5}-1.0 \times 10^{8}\right)\end{array}$ \\
\hline U. urealyticum $\dagger$ & $\stackrel{\mathrm{C}}{\mathrm{V}}$ & $\begin{array}{l}1.9 \times 10^{9} \\
3.2 \times 10^{9}\end{array}$ & $\begin{array}{l}\left(1.0 \times 10^{2}-1.0 \times 10^{10}\right) \\
\left(1.0 \times 10^{1}-1.0 \times 10^{10}\right)\end{array}$ & $\begin{array}{l}9 \cdot 2 \times 10^{7} \\
8.4 \times 10^{8}\end{array}$ & $\begin{array}{l}\left(1.0 \times 10^{1-1.0 \times 10^{9}}\right) \\
\left(1.0 \times 10^{2}-1.0 \times 10^{10}\right)\end{array}$ \\
\hline
\end{tabular}

${ }^{*} \mathrm{C}=$ cervix $; \mathrm{V}=$ vagina

$\dagger$ For U. urealyticum, counts are expressed as colour changing units (ccu).

Gram's stain. Intracellular gram-negative diplococci were observed in gramstained smears of cervical exudate from $11(55 \%)$ of 20 patients with culture-positive gonorrhoea. None of the 17 patients who did not have gonorrhoea had a positive gram-stained smear.

Transformation assay. Cervical or vaginal aspirates from $15(75 \%)$ of the 20 patients with gonorrhoea gave a positive transformation result; cervical aspirates were positive in $13(65 \%)$ and vaginal aspirates in seven $(13 \%)$ patients.

Of the 17 patients with no microbiological evidence of gonorrhoea, two $(11.7 \%)$ gave a positive transformation result. In one of these, a contact of gonorrhoea, both the cervical and vaginal aspirates were positive; only the cervical aspirate was positive in the second patient. The condition diagnosed in both patients was trichomoniasis.

Indirect sandwich ELISA. Specimens from $12(60 \%)$ of the 20 patients with gonorrhoea, gave a positive ELISA result; cervical aspirates were positive in $11(55 \%)$ and vaginal aspirates in one $(5 \%)$.

Cervical aspirates from two $(11.7 \%)$ of the 17 patients with no microbiological evidence of gonorrhoea gave a positive ELISA result. The conditions diagnosed were urinary tract infection in one patient and non-specific genital infection, warts, and pubic lice in the second. Neither woman was a contact of a patient with gonorrhoea.

Limulus lysate assay. The test was positive in $16(84 \cdot 2 \%)$ of 19 patients with cervical gonorrhoea and in three patients $(17.6 \%$ ) with no microbiological evidence of gonorrhoea. The presenting diagnoses of two of these three patients were trichomoniasis and candidiasis respectively. No abnormality was detected in the third patient who was a contact of a man with gonorrhoea. On re-testing secretions from the three patients at a dilution of 1 in 200 , all were negative, thus reducing the false positive rate to zero.

When the secretions from the 16 patients that gave a positive Limulus assay result at a dilution of 1 in 100 were re-tested at 1 in 200, the Limulus-positive-reactor rate was reduced to $13(68 \cdot 4 \%)$ of 19 infected patients. 
TABLE IV

Results obtained with four methods of detecting gonococci in cervical and vaginal aspirates from 20 women with gonorrhoea

\begin{tabular}{|c|c|c|c|c|c|}
\hline $\begin{array}{c}\text { Patient } \\
\text { no. }\end{array}$ & Site & Smear & $\begin{array}{l}\text { Transformation } \\
\text { assay }\end{array}$ & $\begin{array}{c}\text { Indirect } \\
\text { sandwich } \\
\text { ELISA }\end{array}$ & $\begin{array}{l}\text { Limulus } \\
\text { assay }\end{array}$ \\
\hline \multirow[t]{2}{*}{1} & C & - & + & - & - \\
\hline & V & $\ldots$ & + & + & $\ldots$ \\
\hline \multirow[t]{2}{*}{2} & C & + & + & + & + \\
\hline & V & $\cdots$ & + & - & $\ldots$ \\
\hline \multirow[t]{2}{*}{10} & C & - & - & - & + \\
\hline & C & $\ddot{m}$ & - & $\bar{t}$ & 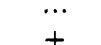 \\
\hline 11 & $\begin{array}{l}\text { C } \\
\text { V }\end{array}$ & $\begin{array}{l}+ \\
\ldots\end{array}$ & $\bar{t}$ & \pm & $\begin{array}{l}+ \\
\ldots\end{array}$ \\
\hline \multirow[t]{2}{*}{13} & C & + & + & + & + \\
\hline & V & $\ldots$ & - & - & $\ldots$ \\
\hline 14 & $\begin{array}{l}\mathrm{C} \\
\mathrm{V}\end{array}$ & - & + & + & $\ldots$ \\
\hline \multirow{2}{*}{15} & C & $\begin{array}{l}\cdots \\
+\end{array}$ & + & + & $\ddot{+}$ \\
\hline & V & $\ldots$ & - & - & 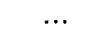 \\
\hline 17 & C & - & + & - & - \\
\hline \multirow{2}{*}{18} & C & $\cdots$ & + & $\bar{t}$ & $\cdots$ \\
\hline & $\mathrm{V}$ & $\overline{-}$ & \pm & $\stackrel{+}{-}$ & $\begin{array}{c}+ \\
\ldots\end{array}$ \\
\hline \multirow[t]{2}{*}{19} & C & - & - & - & + \\
\hline & V & $\ldots$ & - & - & $\ldots$ \\
\hline 22 & C & + & \pm & + & - \\
\hline \multirow[t]{2}{*}{24} & C & - & + & + & $\ddot{t}$ \\
\hline & V & $\ldots$ & + & - & $\cdots$ \\
\hline $26^{*}$ & C & - & + & + & + \\
\hline \multirow{2}{*}{29} & C & $\begin{array}{l}\cdots \\
+\end{array}$ & $\begin{array}{l}+ \\
+\end{array}$ & - & $\begin{array}{l}\cdots \\
+\end{array}$ \\
\hline & V & $\ldots$ & - & - & $\ldots$ \\
\hline 30 & C & + & + & - & + \\
\hline \multirow{2}{*}{31} & C & $\begin{array}{l}\cdots \\
+\end{array}$ & - & - & $\cdots$ \\
\hline & $\mathrm{V}$ & $\begin{array}{l}\top \\
\ldots\end{array}$ & - & - & $\ldots$ \\
\hline 32 & C & - & - & - & + \\
\hline \multirow[t]{2}{*}{33} & C & + & - & $\bar{t}$ & + \\
\hline & $\mathrm{V}$ & $\ldots$ & + & - & \\
\hline \multirow[t]{2}{*}{34} & C & + & - & - & + \\
\hline & V & 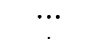 & - & . & \\
\hline \multirow[t]{2}{*}{36} & C & + & + & + & + \\
\hline & V & $\ldots$ & - & - & \\
\hline
\end{tabular}

$\mathrm{C}=$ cervix; $\mathrm{V}=$ vagina; $+=$ positive result; $-=$ negative result; $\ldots=$ not done.

*A positive routine culture was obtained one week after the aspirates had been examined.

\section{Discussion}

The numbers of gonococci in clinical specimens are important when considering the development of a method of detecting gonococcal components. Our data (table I) suggest that any such method should be sensitive enough to detect components derived from as few as $1 \times 10^{2} \mathrm{cfu}$ (vaginal aspirates) or $5 \times 10^{3} \mathrm{cfu}$ (cervical aspirates) of $N$. 
gonorrhoeae per ml of aspirate. These are minimum estimates as non-viable gonococci would also contribute to the total content of DNA, antigen or LPS in aspirates. Assuming that the viable counts at least provide an index of the total amount of gonococcal components present, the wide range of the numbers of gonococci isolated by irrigation of the cervix and vagina indicate that there may be a wide variation in the amounts of products available for detection.

$N$. gonorrhoeae was isolated from the vaginal aspirates of $17(85 \%)$ of the 20 patients with gonorrhoea in this study. Although gonococci have been shown to adhere to vaginal epithelial cells in vitro (Forslin and Danielsson, 1980; Forslin, Danielsson and Falk, 1980), gonococci aspirated from the vaginal pool are probably derived from the cervix, the site of multiplication of the organisms (Ward, Watt and Robertson, 1974). The mean viable count of gonococci in vaginal aspirates $\left(8.4 \times 10^{4}\right.$ $\mathrm{cfu} / \mathrm{ml})$ was considerably lower than that in cervical aspirates $\left(1 \times 10^{6} \mathrm{cfu} / \mathrm{ml}\right)$ although the difference did not attain statistical significance $(p>0.05)$.

Qualitatively, the microflora was similar in cervix and vagina. Quantitatively, however, there were differences. With the exception of the gonococcus, viable counts in aspirates from the vagina were approximately two to tenfold greater than the corresponding counts from the cervix. Staphylococci were isolated more frequently from the aspirates from patients with gonorrhoea. Organisms isolated only from patients with no microbiological evidence of gonorrhoea were haemolytic streptococci, E. coli, C. albicans and T. vaginalis. Unfortunately, an agar overlay assay of the type described by Saigh, Sanders and Sanders (1978) was not performed to determine whether the isolates in the present study were inhibitory to gonococci.

A positive transformation result was obtained with material aspirated from the cervix or vagina of only $75 \%$ of the patients with gonorrhoea. When crude DNA preparations from 169 clinical isolates from the same locality were tested in an earlier study (Sarafian and Young, 1980) c. 90\% gave a positive transformation result. Therefore, negative transformation results with aspirates from patients with gonorrhoea were unlikely to be due to proline auxotrophy of donor gonococci. Insufficient numbers of gonococci also seems unlikely to be the cause of the five false-negative transformation results because aspirates from each of these patients yielded more than $1.7 \times 10^{3} \mathrm{cfu} / \mathrm{ml}$, the minimum amount detectable by the transformation assay (Sarafian and Young, 1980). Enzymic degradation of DNA present in the aspirates may account for the false-negative results. We disagree with Janik, Juni and Heym (1976) who considered that genetic transformation was a simple, rapid and sensitive method of detecting gonococci in clinical specimens.

The indirect sandwich ELISA detected gonococcal antigens in aspirates from only $60 \%$ of infected women. In our earlier work (Sarafian and Young, 1982) the minimum number of gonococci detectable was $6.6 \times 10^{3} \mathrm{cfu}$ which corresponds to $3.7 \times 10^{4}$ $\mathrm{cfu} / \mathrm{ml}$ when a $180-\mu \mathrm{l}$ portion is tested. Although $58 \%$ and $16 \%$ of cervical and vaginal aspirates respectively had numbers of gonococci above the minimum level, the detection of antigen did not correlate well with the numbers of viable gonococci isolated. Six of nine cervical aspirates with numbers of gonococci judged insufficient to be detectable by the assay gave a positive ELISA result whereas only five of eleven aspirates with sufficient numbers of gonococci gave a positive result. This lack of correlation could be explained if the ELISA depended largely on soluble antigen. 
The Limulus lysate assay detected $84.2 \%$ of infected women and was clearly the most sensitive non-cultural method of diagnosing gonococcal infection. The Limulus assay, in detecting endotoxin, cannot be held to be specific; its significance in relation to the diagnosis of gonorrhoea depends upon the premise that other endotoxin-positive organisms are unlikely to produce sufficient amounts of endotoxin at the sites sampled. Moreover, at dilutions of secretions at which gonococci gave a positive result in the Limulus lysate assay, the presence of other endotoxin-positive bacteria did not seem to interfere with the results. Aspirates from three patients with no microbiological evidence of gonorrhoea were shown to contain endotoxin-positive bacteria but a negative Limulus result was obtained in each case. However, an unexplained positive result was obtained with secretions from three other patients without gonorrhoea. Retesting positive specimens at a dilution of 1 in 200 reduced the unexplained positive rate to zero but also reduced the true positive rate from $84 \cdot 2 \%$ to $68.4 \%$. It is suggested that further standardisation of specimens before testing could improve the sensitivity and the specificity of the Limulus lysate assay. Recently a test device has been developed to simplify and standardise the collection, dilution and testing of urethral exudates from men (Prior and Spagna, 1981). A similar approach to the problem of sampling cervical exudates merits study.

A major disadvantage of all of the above methods is that gonococci are not available for antibiotic sensitivity testing. This has become increasingly important with the discovery and increasing incidence of beta-lactamase-producing strains of $N$. gonorrhoeae. Perhaps some rapid method of detecting gonococcal beta-lactamase in secretions could also be developed and this would be complementary to the present approach. Another limitation of these methods in comparison with culture is related to diagnosis of infection in the rectum and pharynx. In spite of these limitations, we believe that the development of methods to detect gonococcal components is a worthwhile objective and could make a significant contribution to the rapid diagnosis and control of gonococcal infection. Of the methods examined, the Limulus lysate assay and an ELISA system are particularly worthy of further investigation. Because of the large numbers of gonococci and lower numbers of other organisms in cervical aspirates these are preferred to vaginal aspirates for the future development of such tests.

This work was supported in part by a grant from the Scottish Home and Health Department (research grant no. K/MRS/50/C22) whose financial assistance is gratefully acknowledged. We also thank Professor J.G. Collee for his helpful advice in the preparation of this paper.

\section{REFERENCES}

BAWDON, R. E., JUNI, E. AND BRITT, E. M. 1977. Identification of Neisseria gonorrhoeae by genetic transformation: a clinical laboratory evaluation. Journal of Clinical Microbiology, 5, 108-109.

Collee, J. G., Watt, B., Fowler, E. B. and Brown, R. 1972. An evaluation of the Gaspak system in the culture of anaerobic bacteria. Journal of Applied Bacteriology, 35, 71-82.

Cowan, S. T. 1974. Cowan and Steel's Manual for the identification of medical bacteria, 2nd ed. Cambridge University Press, Cambridge.

Forslin, L. AND Danielsson, D. 1980. In vitro studies of the adherence of Neisseria gonorrhoeae and other urogenital bacteria to vaginal and uroepithelial cells with special regard to the menstrual cycle. Gynecologic and Obstetric Investigation, 11, 327-340.

Forslin, L., DanielsSON, D. AND FalK, V. 1980. Adherence in vitro of Neisseria gonorrhoeae, 
Escherichia coli and group B streptococci to vaginal epithelial cells of post menopausal women. Gynecologic and Obstetric Investigation, 11, 341-349.

JANIK, A., JUNI, E. AND HeYM, G. A. 1976. Genetic transformation as a tool for detection of Neisseria gonorrhoeae. Journal of Clinical Microbiology, 4, 71-81.

Kellogg, D. S., Peacock, W. L., Deacon, W. E., Brown, L. and Pirkle, C. I. 1963. Neisseria gonorrhoeae. I. Virulence genetically linked to clonal variation. Journal of Bacteriology, $85,1274-1279$.

Lowe, T. L. AND Kraus, S. J. 1976. Quantitation of Neisseria gonorrhoeae from women with gonorrhea. Journal of Infectious Diseases, 133, 621-626.

Prior, R. B. AND SPAGNA, V. A. 1981. Application of a Limulus test device in rapid evaluation of gonococcal and nongonococcal urethritis in males. Journal of Clinical Microbiology, 14, 256-259.

SAIGH, J. H., SANDERS, C. C. AND SANDERS, W. E. 1978. Inhibition of Neisseria gonorrhoeae by aerobic and facultatively anaerobic components of the endocervical flora: evidence for a protective effect against infection. Infection and Immunity, 19, 704-710.

SARAFIAN, S. K. AND Young, H. 1980. Identification of pathogenic neisseriae by genetic transformation. Journal of Medical Microbiology, 13, 291-296.

SaRAfIan, S. K. AND Young, H. 1982. Detection of gonococcal antigens by an indirect sandwich enzyme-linked immunosorbent assay. Journal of Medical Microbiology, 15, $541-550$.

Spagna, V. A., Prior, R. B. ANd Perkins, R. L. 1979. Rapid presumptive diagnosis of gonococcal urethritis in men by the Limulus lysate test. British Journal of Venereal Diseases, 55, 179-182.

Spagna, V. A., Prior, R. B. and Perkins, R. L. 1980. Rapid presumptive diagnosis of gonococcal cervicitis by the Limulus lysate assay. American Journal of Obstetrics and Gynecology, 137, 595-599.

Sud, I. J. AND FeINGOLD, D. S. 1979. Detection of 3-hydroxy fatty acids, at picogram levels in biologic specimens. A chemical method for the detection of Neisseria gonorrhoeae? Journal of Investigative Dermatology, 73, 521-526.

TAKEGUCHI, M. M., and six others. 1980. The occurrence of 1,2-propanediol oxidoreductase in microorganisms and its use as a possible diagnostic marker for Neisseria gonorrhoeae. Journal of General Microbiology, 119, 459-464.

Taschdjian, C. L., Burchall, J. J. AND Kozinn, P. J. 1960. Rapid identification of Candida albicans by filamentation on serum and serum substitutes. American Journal of Diseases of Children, 99, 212-215.

Thomas, B. J., Evans, R. T., Hutchinson, G. R. and Taylor-Robinson, D. 1977. Early detection of chlamydial inclusions combining the use of cycloheximide-treated McCoy cells and immunofluorescence staining. Journal of Clinical Microbiology, 6, 285-292.

Thornley, M. J., Wilson, D. V., De Hormaeche, R. D., OAtes, J. K. and Coombs, R. R. A. 1979. Detection of gonococcal antigens in urine by radioimmunoassay. Journal of Medical Microbiology, 12, 161-175.

WARD, M. E., WATt, P. J. AND RoBertson, J. N. 1974. The human fallopian tube: a laboratory model for gonococcal infection. Journal of Infectious Diseases, 129, 650-659.

Young, H. 1978a. Identification and penicillinase testing of Neisseria gonorrhoeae from primary isolation cultures on modified New York City Medium. Journal of Clinical Microbiology, 7, 247-250.

Young, H. 1978b. Cultural diagnosis of gonorrhoea with modified New York City (MNYC) medium. British Journal of Venereal Diseases, 54, 36-40.

YounG, H. 1981. Advances in routine laboratory procedures for the diagnosis of gonorrhoea. In Recent advances in sexually transmitted diseases, Vol. 2, edited by J. R. W. Harris, Churchill Livingstone, Edinburgh, pp. 59-71.

Young, H., Sarafian, S. K. AND McMillan, A. 1981. Reactivity of the limulus lysate assay with uterine cervical secretions. A preliminary evaluation. British Journal of Venereal Diseases, 57, 200-203.

YOUNG, H., TUACH, S. AND BAIN, S. S. R. 1981. Incidence of Ureaplasma urealyticum infection in women attending a clinic for sexually transmitted diseases. Journal of Infection, 3, 258-265. 